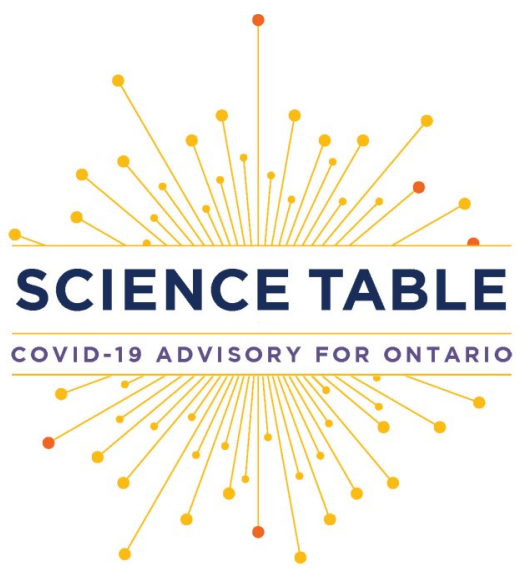

Version 1.0

Published: April 22, 2021

Citation: Desveaux L, Mosher R, Buchan JL, et al. Behavioural science principles for enhancing adherence to public health measures. Science Briefs of the Ontario COVID-19 Science Advisory Table. 2021;2(24). https://doi.org/10.47326/ocsat.2021.02.24.1.0

Author Affiliations: The affiliations of the members of the Ontario COVID-19 Science Advisory Table can be found at https:// covid19-sciencetable.ca/.

Declarations of Interest: The declarations of interest of the members of the Ontario COVID-19 Science Advisory Table can be found at https://covid19-sciencetable.ca/.

About Us: The Ontario COVID-19 Science Advisory Table is a group of scientific experts and health system leaders who evaluate and report on emerging evidence relevant to the COVID-19 pandemic, to inform Ontario's response. Our mandate is to provide weekly summaries of relevant scientific evidence for the COVID-19 Health Coordination Table of the Province of Ontario, integrating information from existing scientific tables, Ontario's universities and agencies, and the best global evidence. The Science Table summarizes its findings for the Health Coordination Table and the public in Science Briefs.

The Behavioural Science Working Group is a group of scientific experts and public health leaders with specific expertise in behaviour change. Their expertise spans behavioural medicine, health, clinical and social psychology, behavioural economics, and implementation science. The Working Group evaluates emerging scientific evidence related to vaccination in healthcare workers and the general population, alongside other recommended protective behaviours such as physical distancing, mask-wearing, testing, and supported quarantine. The Working Group reports its findings to the public and the Science Table. Its findings are also summarized in Science Briefs.

Correspondence to: Secretariat of the Ontario COVID-19 Science Advisory Table (info@covid19-sciencetable.ca)

\section{SCIENCE BRIEFS}

Behavioural Science Principles for Enhancing Adherence to Public Health Measures

Laura Desveaux, Rhiannon Mosher, Judy L. Buchan, Rachel Burns, Kimberly M. Corace, Gerald A. Evans, Leandre R. Fabrigar, Brian Schwartz, Nathan M. Stall, Ashini Weerasinghe, Justin Presseau, on behalf of the Behavioural Science Working Group and the Ontario COVID-19 Science Advisory Table

\section{Key Message}

The science of getting people to start something new is different from the science of getting them to continue positive behaviours. Amid rising rates of new SARS-CoV-2 variants of concern, Ontario needs a refreshed approach to maintaining and enhancing adherence to public health measures. Promising strategies to increase effective masking and physical distancing include persuasion, enablement, modelling the behaviour, and clear education.

\section{Background}

Effective COVID-19 vaccines signal hope that the pandemic may be drawing to an end, but Ontario is months away from fully vaccinating its population of about 15million individuals. Meanwhile, Ontario has entered a third wave of the pandemic with the rapid spread of more transmissible SARS-CoV-2 variants of concern (VOCs) which are both more transmissible and associated with more severe clinical outcomes. ${ }^{1}$ Avoiding shared indoor spaces, physical distancing and wearing a mask remain the most important behaviours for Ontarians to protect themselves and those around them. Now more than a year into the pandemic, messaging and experience have helped to establish a variety of positive physical distancing and masking habits among Ontarians. There is an opportunity to capitalize on these existing behaviours to enhance and reinvigorate adherence to staying outdoors, physical distancing and masking. Increasing the number of people following these protective behaviours may curb the threat of VOCs and help Ontario enjoy a better summer.

Adherence to masking and distancing has become a habit for most Canadians, with $86 \%$ reporting wearing a face mask in public and $75 \%$ reporting following physical distancing guidelines. ${ }^{2}$ While these successful behavioural changes should be recognized, these data also highlight an opportunity to support enhanced adherence to both physical distancing and masking. While $80 \%$ of Canadians report the ability to continue following these measures for at least the next six months, the majority are getting tired of following COVID-19 public health measures. ${ }^{2}$ Capitalizing on existing habits while empathizing with fatigue requires a renewed and evidence-based approach to supporting public health measures that draws on behavioural science.

\section{Understanding COVID-19 Fatigue}

The pandemic has taken a toll on all Ontarians and some feel as though public health measures do not consider the unique impact these measures have on mental health and wellbeing. For example, focus groups conducted in early 2021 identified that young Ontarians (18-24 years of age) are overwhelmed by daily updates and 
Copyright: 2021 Ontario COVID-19 Science

Advisory Table. This is an open access document distributed under the terms of the Creative Commons Attribution License, which permits unrestricted use, distribution, and reproduction in any medium, provided that the original work is properly cited.

The views and findings expressed in this Science Brief are those of the authors and do not necessarily reflect the views of all of the members of the Ontario COVID-19 Science Advisory Table, its Working Groups, and its partners.

confused about the provincial messaging regarding the colour-coded COVID-19 response framework. ${ }^{3}$ While young adults reported "mostly" following public health measures, fatigue may lead to complacency towards measures as Ontarians actively juxtapose what COVID-19 has "taken away" from them against their risk of adverse consequences from contracting SARS-CoV-2 itself. $^{4}$

\section{Questions}

What behaviour change strategies can support maintaining already established behaviours?

What behaviour change strategies can support enhanced adherence to public health measures among those who don't realize they aren't complying?

Who is in a position to act on renewed strategies?

\section{Findings}

In this Science Brief, we focus on two key public health measures: physical distancing and masking. The tables below are intended to guide the reader by identifying barriers and selecting solutions with the following questions: "Which barriers do residents in my region face?" and "What strategies can we use to further support and enhance public adherence to public health measures?"

In line with best practices in behavioural science, ${ }^{5,6}$ we encourage the use of as many unique strategies as possible to maximize impact. Below, we present known barriers and behaviour change strategies that can each be used to address issues of capability, opportunity and motivation - the three key determinants of whether or not an individual behaviour is carried out. ${ }^{7}$ Suggestions on how to operationalize theses strategies recognize that mitigating the severity of the COVID-19 pandemic requires the collaborative effort of public leaders, community leaders, healthcare organizations, and the general public. ${ }^{8}$ As such, the strategies are explicitly linked to target groups in a position to action them to support two key groups of Ontarians:

1. Those who are already adhering to physical distancing and masking in most situations but are unclear on the remaining high-risk scenarios that exist in their lives (focus on maintenance).

2. Those who are inconsistently following these public health measures due to easily addressed capability, opportunity and motivation reasons (focus on enhancement).

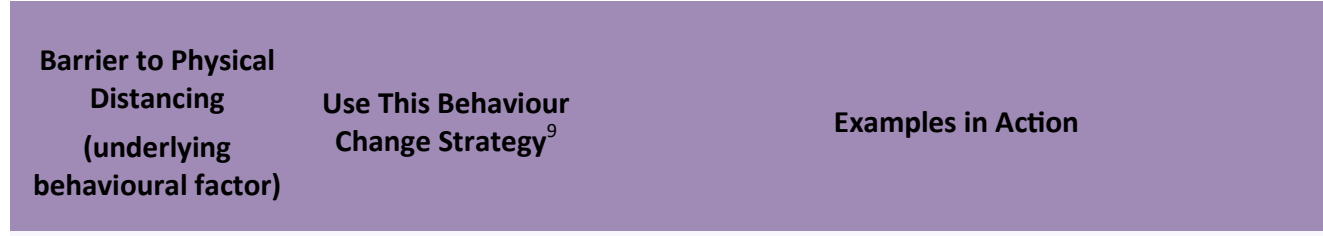

"It feels like there is nothing we can do, so why try" or "All or nothing" thinking (100\% adherence or it doesn't make a difference)

(Behavioural regulation)
Tips for public and community leaders:

- As we move into warmer weather, encourage and normalize outdoor gatherings where physical distance is maintained

- Allow businesses to use and re-purpose outdoor space wherever possible (e.g., provide expanded outdoor dining areas on the street or sidewalk ${ }^{10}$

- Identify common areas (parks, open areas) where there is enough space for people to safely gather, and promote their use 
Tips for public and community leaders:

Hard to ask others to respect your space or remain distanced

(Social influence; Lack of confidence)
Modelling

- Ask for the help of local leaders and influential community members to recognize challenges and share their strategies for a COVID-19 safe community

- Work with communities to establish adapted cultural norms re: physical contact and distance

- Plan how to tailor communications to people who might be missed, such as those speaking minority languages $^{11}$

\section{Tips for public and community leaders:}

- Highlight that every effort counts ("It's not an all-ornothing situation - every opportunity counts"; "Small efforts make a big difference")

Conflicting messaging re: distancing while outdoors

(Lack of knowledge)
Education

- Leverage metaphors ("A steady drip of water can create a cave") and visuals that help demonstrate how small repetitive events lead to big outcomes

- Use consistent, actionable messages from different sources and disseminate in multiple ways (platforms, methods or channels) ${ }^{12,13}$

- Be clear and acknowledge the uncertainty regarding the duration of measures, and that they could extended or reduced ${ }^{11}$

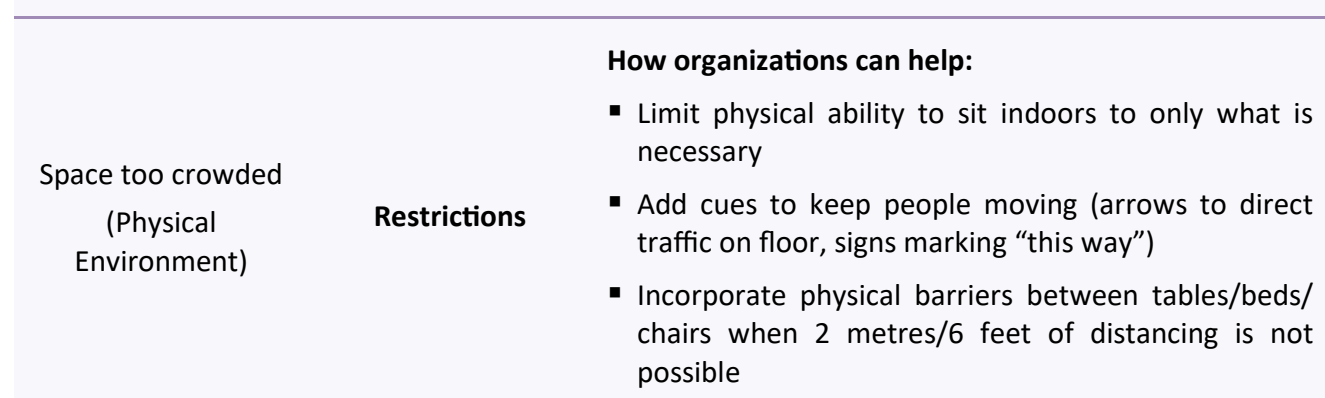

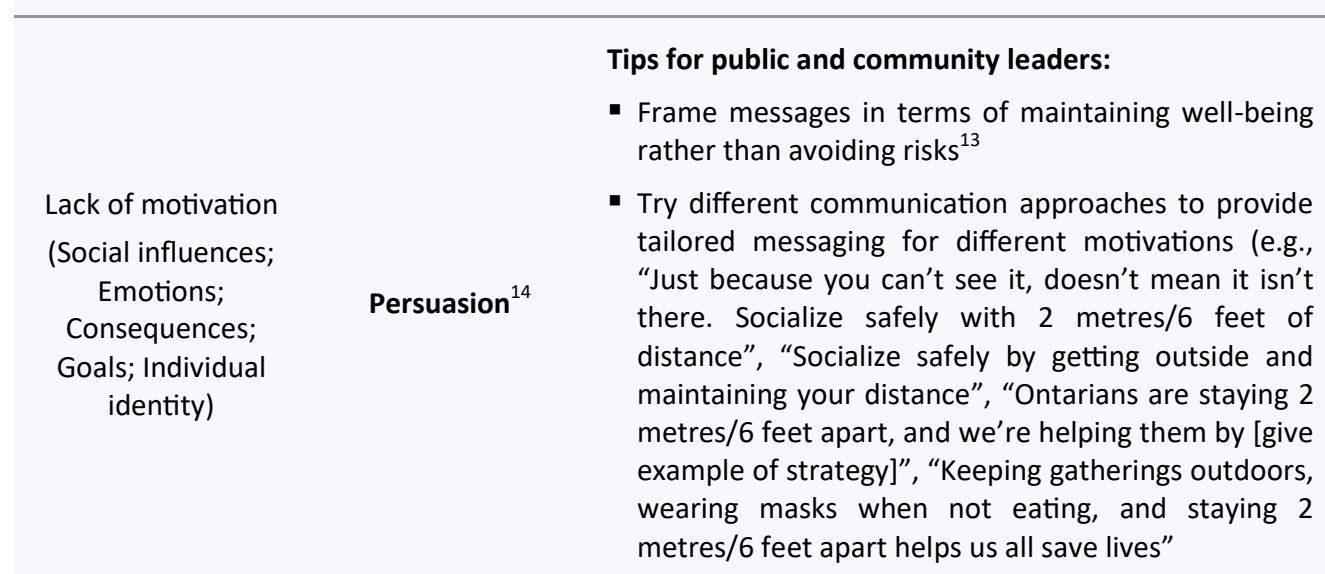

\begin{tabular}{|c|c|c|}
\hline $\begin{array}{l}\text { Not adhering to the } \\
2 \text { metre/ } 6 \text { foot }\end{array}$ & & What can be done at home and in the community: \\
\hline $\begin{array}{l}\text { distancing } \\
\text { requirement } \\
\text { (Reinforcement; } \\
\text { Establish habits) }\end{array}$ & Incentivization & $\begin{array}{l}\text { - Social rewards (e.g., creating spaces to safely } \\
\text { socialize with those outside your household) }\end{array}$ \\
\hline
\end{tabular}

\footnotetext{
Uncomfortable/ Unsure how to ask others to remain distanced

(Lack of skills)
}

Training

\section{What can be done at home and in the community:}
- Lighten the situation with anecdotes that add humour


Accommodation to existing signage

(Environmental context; Available resources; Memory)

\section{How organizations can help:}

- Add new floor markings and posters. Arrange seating and furniture in common areas at a safe distance
Environmental Restructuring
- Draw circles in outdoor areas to show safe areas for socializing with remaining space for 'through traffic only'

- Provide chairs and benches in outdoor areas that are 2 metres/ 6 feet apart to reinforce proper distance

Table 1. Strategies to Maintain and Enhance Adherence to Physical Distancing

\section{Barrier to Wearing a \\ Mask \\ (underlying \\ behavioural factor)}

Examples in Action

$$
\begin{gathered}
\text { Not motivated to } \\
\text { adhere }{ }^{15} \\
\text { (Personal goals; } \\
\text { Social influences; } \\
\text { Emotion; Beliefs } \\
\text { about } \\
\text { consequences; }{ }^{16} \\
\text { Individual identity) }
\end{gathered}
$$

Tips for public and community leaders:

- Remind people what they could miss out on if not wearing a mask (e.g., trigger a fear of missing out with messages like - "Masking now helps deliver a better summer")

- Stay the course: foster satisfaction with progress to date by making it clear how wearing a mask effectively is making a difference towards Ontario having a better summer

Persuasion

What can be done at home and in the community:

- Use reminders and prompts to build social norms, such as educational posters at the entrance and exit of community buildings

- Choose a different, positive framing: Personally frame masking as showing others you care ("I mask because I care about X")

- Leverage fashion/fun motives, such as masks being a form of expression and identity

\section{Tips for public and community leaders:}

- Use clear and simple messages about where and when wearing masks is required ${ }^{17}$ (e.g., every time you are in close to proximity to others who live outside your household)

Unsure what to do in atypical settings

(Support regulating behaviour)
Enablement

- Prevent all or nothing thinking - each time you wear a mask counts

What can be done at home and in the community:

- Provide concise, simple self-rules (e.g., I keep a mask with me any time I leave my home)

- Have a back up plan: Include masks in purses/bags/ coat pockets to guard against forgetting a mask or reusing a wet mask
Seeing others unmasked

(Social influences; Beliefs about capabilities)

\section{Tips for public and community leaders:}

- Use messaging from people we identify with helps embed an equity lens (i.e., those that look like me, have a similar job or life responsibilities, and do the things I do/want to do), with grassroots or community-based messaging often being most powerful 
- Build norms around masking by telling Ontarians how many are wearing masks regularly in their community and show a variety of people wearing masks in commercials and on posters to keep fostering masking as normal behaviour

- Lead by example: trusted sources as well as those with high visibility (government and media) need to consistently model masking

\begin{tabular}{|c|c|c|}
\hline $\begin{array}{l}\text { Wearing mask } \\
\text { incorrectly } \\
\text { (Need to build } \\
\text { knowledge) }\end{array}$ & Education & $\begin{array}{l}\text { Tips for public and community leaders: } \\
\text { - Signal the need for a 'mask refresher' to prompt } \\
\text { Ontarians to reflect on proper masking } \\
\text { - Provide new instructions with clear images that have } \\
\text { not been seen before to increase attention } \\
\text { What can be done at home and in the community: } \\
\text { - Use reminders and prompts to encourage proper } \\
\text { use, such as a 'mask bin' at the front door, } \\
\text { prompting mask washing after each use (at home) }\end{array}$ \\
\hline $\begin{array}{l}\text { Assumptions that } \\
\text { one is wearing a } \\
\text { mask properly } \\
\text { (Need to build } \\
\text { skillset) }\end{array}$ & Training & $\begin{array}{l}\text { Tips for public and community leaders: } \\
\text { - Mask better: Produce and disseminate clear videos } \\
\text { and images outlining what we have learned about } \\
\text { how to mask better; 'Mask hacks' from credible } \\
\text { sources show people how to mask properly versus } \\
\text { simply telling them (i.e., video or image formats) } \\
\text { How organizations can help: } \\
\text { - Where possible, have personnel near the entrance of } \\
\text { a public building demonstrating proper mask } \\
\text { wearing technique }\end{array}$ \\
\hline $\begin{array}{l}\text { Inconsistent use of } \\
\text { masks across } \\
\text { settings } \\
\text { (Environmental } \\
\text { context) }\end{array}$ & Restrictions & $\begin{array}{l}\text { Tips for public and community leaders: } \\
\text { - Clearly communicate where and when access is } \\
\text { restricted unless wearing a mask } \\
\text { - Ensure masks are available to reinforce mask } \\
\text { wearing and do not limit access based on mask } \\
\text { access } \\
\text { How organizations can help: } \\
\text { - Where signs have already been in place for many } \\
\text { months, refresh with newly designed versions to } \\
\text { make them noticeable again } \\
\text { - Messages about restrictions should be clear at the } \\
\text { entry point to any public indoor setting and in } \\
\text { common outdoor areas (e.g., parks, trails) using a } \\
\text { variety of communication modalities (e.g., signage) }\end{array}$ \\
\hline $\begin{array}{l}\text { Positive outcomes } \\
\text { or progress is } \\
\text { unclear } \\
\text { (Memory; Establish } \\
\text { habits) }\end{array}$ & Incentivization & $\begin{array}{l}\text { Tips for public and community leaders: } \\
\text { - Provide a tax credit for businesses to support the } \\
\text { provisions of masks in workplaces } \\
\text { - Pulling together: thank Ontarians for masking } \\
\text { How organizations can help: } \\
\text { - Ensure consistency by requiring masks for entry into } \\
\text { any and all public indoor spaces at all times, for all } \\
\text { Ontarians (irrespective of vaccination status) } \\
\text { - Highlight the activities that can be done safely (i.e., } \\
\text { gathering outside }{ }^{18} \text { and socializing within stated } \\
\text { gathering size limits) if masks are worn }\end{array}$ \\
\hline
\end{tabular}




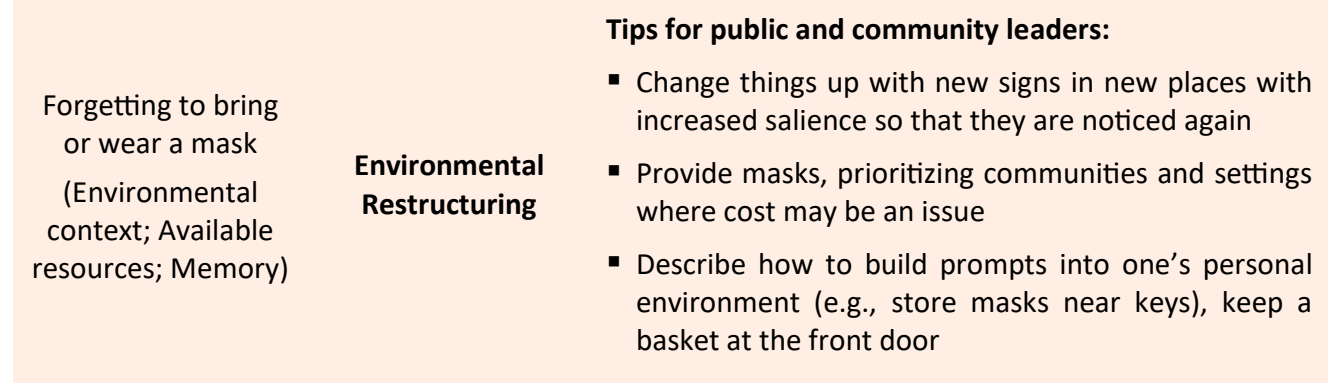

Table 2. Strategies to Maintain and Enhance Effective Mask Use

\section{Interpretation}

Governments, public health units, and healthcare organizations are delivering strategies to support Ontarians in adhering to public health measures, with an emphasis on physical distancing and masking. This Science Brief recognizes that more than a year into the COVID-19 pandemic, we need to move beyond "more of the same" when it comes to strategies to maintain and enhance how, when, and where Ontarians engage in masking and distancing. Groups in a position to support change can leverage behavioural science to refresh their approaches by using a range of evidence-based behavioural change strategies. These strategies can help to move beyond asking Ontarians to "do more" (potentially contributing to pandemicfatigue) and instead focus on creating the conditions needed to ensure ongoing adherence in our current state.

\section{Methods Used for This Science Brief}

The advice on this brief has been developed using the COM-B model. ${ }^{9}$ COM-B is a theoretical framework employed by Behavioural Scientists to help identify key behavioural barriers to desired action. The model identifies three essential conditions: Capability, Opportunity, Motivation that affect Behaviour and decisionmaking. Capability barriers include lack of knowledge and comprehension about a behaviour and its consequences, and lack of skill necessary to carry out a behaviour. Opportunity barriers include time and resource constraints that make a desired behaviour more difficult or costly to carry out. Motivation barriers include emotional reactions and inaccurate beliefs that create obstacles for carrying out a behaviour.

\section{Author Contributions}

LD and JP conceived the Science Brief. LD wrote the first draft. All authors revised the Science Brief critically for important intellectual content and approved the final version.

The authors would like to acknowledge Dr. Samantha Meyer for her support in understanding the attitudes of young adults as it relates to public health measures during the COVID-19 pandemic and members of the Ontario Behavioural Insights Unit for their advice on public health measure adherence.

\section{References}

1. Tuite AR, Fisman DN, Odutayo A, et al. COVID-19 hospitalizations, ICU admissions and deaths associated with the new variants of concern. Sci Briefs Ont COVID-19 Sci Advis Table. 2021;1(18). https://doi.org/10.47326/ ocsat.2021.02.18.1.0 
2. Wave 10 Results. Impact Canada. Accessed March 24, 2021. https:// impact.canada.ca/en/challenges/cosmo-canada/results/wave10

3. Government of Ontario. COVID-19 response framework: keeping Ontario safe and open. Ontario.ca. Published November 3, 2020. Accessed March 11, 2021. https://www.ontario.ca/page/covid-19-response-framework-keeping-ontariosafe-and-open

4. Data were collected as part of CIHR \#440293 led by E. Dubé, Laval. (Samantha Meyer, PhD, personal communication, March 18, 2021.)

5. Baker R, Camosso-Stefinovic J, Gillies C, et al. Tailored interventions to overcome identified barriers to change: effects on professional practice and health care outcomes. Cochrane Database Syst Rev. 2010;(3). https:// doi.org/10.1002/14651858.CD005470.pub2

6. Noar SM, Benac CN, Harris MS. Does tailoring matter? Meta-analytic review of tailored print health behavior change interventions. Psychol Bull. 2007;133 (4):673-693. https://doi.org/10.1037/0033-2909.133.4.673

7. McDonagh LK, Saunders JM, Cassell J, et al. Application of the COM-B model to barriers and facilitators to chlamydia testing in general practice for young people and primary care practitioners: a systematic review. Implement Sci IS. 2018;13(1):130. https://doi.org/10.1186/s13012-018-0821-y

8. Ng T-C, Cheng $\mathrm{H}-\mathrm{Y}$, Chang $\mathrm{H}-\mathrm{H}$, et al. Comparison of estimated effectiveness of case-based and population-based interventions on COVID-19 containment in Taiwan. JAMA Intern Med. Published online April 6, 2021. https:// doi.org/10.1001/jamainternmed.2021.1644

9. Michie S, van Stralen MM, West R. The behaviour change wheel: A new method for characterising and designing behaviour change interventions. Implement Sci. 2011;6(1):42. https://doi.org/10.1186/1748-5908-6-42

10. City of Toronto. COVID-19: CaféTO. City of Toronto. Published 2021. https:// www.toronto.ca/home/covid-19/covid-19-protect-yourself-others/covid-19reduce-virus-spread/covid-19-cafeto/

11. Ryan RE, Parkhill A, Schoenfeld L, et al. What are relevant, feasible and effective approaches to promote acceptance, uptake and adherence to physical distancing measures for COVID-19 prevention and control? Published 2021. https://www.euro.who.int/en/health-topics/health-emergencies/coronaviruscovid-19/publications-and-technical-guidance/public-health-and-socialmeasures/what-are-relevant,-feasible-and-effective-approaches-to-promoteacceptance,-uptake-and-adherence-to-physical-distancing-measures-for-covid19-prevention-and-control-2021

12. Zhu Y, Fu K-W, Grépin KA, Liang H, Fung IC-H. Limited Early Warnings and Public Attention to Coronavirus Disease 2019 in China, January-February, 2020: A Longitudinal Cohort of Randomly Sampled Weibo Users. Disaster Med Public Health Prep. 2020;14(5):e24-e27. https://doi.org/10.1017/dmp.2020.68

13. Qazi A, Qazi J, Naseer K, et al. Analyzing situational awareness through public opinion to predict adoption of social distancing amid pandemic COVID-19. J Med Virol. 2020;92(7):849-855. https://doi.org/10.1002/jmv.25840

14. Lunn PD, Timmons S, Belton CA, Barjaková M, Julienne H, Lavin C. Motivating social distancing during the COVID-19 pandemic: an online experiment. Soc Sci Med 1982. 2020;265:113478. https://doi.org/10.1016/j.socscimed.2020.113478

15. Egan M, Phillips R, Roy-Chowdhury V, Xu Y. How to wear a facemask - results 
from an experiment with 4,099 UK adults. Published May 19, 2020. https:// www.bi.team/blogs/how-to-wear-a-facemask-results-from-an-experiment-with4099-uk-adults/

16. Hendrix MJ, Walde C, Findley K, Trotman R. Absence of apparent transmission of SARS-CoV-2 from two stylists after exposure at a hair salon with a universal face covering policy - Springfield, Missouri, May 2020. MMWR Morb Mortal Wkly Rep. 2020;69. https://doi.org/10.15585/mmwr.mm6928e2

17. Brown D, Perera D, Kettle S. COVID-19 prevention: too much information? Published August 7, 2020. https://www.bi.team/blogs/covid-19-prevention-toomuch-information/

18. Bulfone TC, Malekinejad M, Rutherford GW, Razani N. Outdoor Transmission of SARS-CoV-2 and Other Respiratory Viruses: A Systematic Review. J Infect Dis. 2021;223(4):550-561. https://doi.org/10.1093/infdis/jiaa742 